\title{
Wildland Fire Superintendent Dies From Heart Attack After Performing Physical Fitness Training - Idaho
}

\section{Executive Summary}

On June 10, 2015, a 33-year-old career, seasonal wildland fire superintendent (the "Superintendent") completed physical fitness training. The training included a 1.8-mile trail run on a trail over rolling hills. The Superintendent completed the run at a 5.4-mile per hour pace. Following the run, he talked with crewmembers in the fire office. He reported no signs or symptoms of cardiac problems, but suddenly collapsed. Cardiopulmonary resuscitation (CPR) was initiated, 911 was notified, and an ambulance and air evacuation medical helicopter were dispatched. Despite treatment for 43 minutes, the Superintendent's condition did not improve. Ambulance and air evacuation paramedics conferred with the emergency department physician. Following the physician's guidance they pronounced the Superintendent dead at the scene.

The death certificate and the autopsy report listed the cause of death as "acute coronary artery thrombosis," commonly known as a heart attack. NIOSH investigators conclude that the exertion of the training precipitated the heart attack.

\section{Key Recommendations}

The following recommendations address general safety and health issues and would not have prevented the Superintendent's death:

- Provide annual medical evaluations to all wildland fire fighters consistent with 5 CFR 339, Medical Qualification Determinations, and NFPA 1582, Standard on Comprehensive Occupational Medical Program for Fire Departments

- Ensure that wildland fire fighters are cleared for duty by a physician knowledgeable about the physical demands of wildland fire fighting, the personal protective equipment used by wildland fire fighters, and the medical fitness for duty guidelines for fire fighters contained in NFPA 1582

- Ensure automated external defibrillators (AEDs) are readily available as part of the basic life support equipment 


\section{Wildland Fire Superintendent Dies From Heart Attack After Performing Physical Fitness Training - Idaho}

The National Institute for Occupational Safety and Health (NIOSH), an institute within the Centers for Disease Control and Prevention (CDC), is the federal agency responsible for conducting research and making recommendations for the prevention of work-related injury and illness. In 1998, Congress appropriated funds to NIOSH to conduct a fire fighter initiative that resulted in the NIOSH "Fire Fighter Fatality Investigation and Prevention Program" which examines line-of-duty-deaths or on duty deaths of fire fighters to assist fire departments, fire fighters, the fire service and others to prevent similar fire fighter deaths in the future. The agency does not enforce compliance with State or Federal occupational safety and health standards and does not determine fault or assign blame. Participation of fire departments and individuals in NIOSH investigations is voluntary. Under its program, NIOSH investigators interview persons with knowledge of the incident who agree to be interviewed and review available records to develop a description of the conditions and circumstances leading to the death(s). Interviewees are not asked to sign swom statements and interviews are not recorded. The agency's reports do not name the victim, the fire department or those interviewed. The NIOSH report's summary of the conditions and circumstances surrounding the fatality is intended to provide context to the agency's recommendations and is not intended to be definitive for purposes of determining any claim or benefit.

For further information, visit the program website at www.cdc.gov/niosh/fire or call toll free 1-800-CDC-INFO (1-800-232-4636). 


\section{Death in the line of duty... \\ Niosh \\ and Prevention Program}

\section{Wildland Fire Superintendent Dies From Heart Attack After Performing Physical Fitness Training - Idaho}

\section{Introduction}

On June 10, 2015, a 33-year-old male career-seasonal wildland fire superintendent had a fatal heart attack after completing required physical fitness training. NIOSH was notified of this fatality on June 15, 2015, by the U.S. Fire Administration. NIOSH contacted the affected agency (the "Agency") on June 16, 2015, to gather additional information and on November 20, 2015, to initiate the investigation. On December 1, 2015 a safety and occupational health specialist from the NIOSH Fire Fighter Fatality Prevention and Investigation Program conducted an on-site investigation of the incident. Investigators also included an occupational safety and health specialist and an epidemiologist from the NIOSH Wildland Fire Fighting Program.

During the investigation, NIOSH personnel interviewed the following people:

- Fire Management Officer

- Acting Fire Management Officer

- Fire Crew Supervisor

- National Fire Safety Specialist

- Medical Standards Program Manager

- Superintendent's spouse

NIOSH personnel reviewed the following documents:

- Agency annual report for 2014

- Emergency medical service (ambulance) report

- Air ambulance report

- Death certificate

- Autopsy report

- Agency medical evaluation records

- Agency medical standards

\section{Investigation}

On June 7, 2015, the Superintendent reported for work at 0600 hours and his crew was dispatched to a nearby wildland fire. They performed a mobile attack on the fireline and mop-up functions. Weather conditions for that day reached a peak temperature of $89^{\circ}$ Fahrenheit with 22 percent relative humidity [NOAA 2015a]. The Superintendent ended his work shift at 2000 hours and camped overnight with his crew at the fire scene. Over the next 2 days, the Superintendent and his crew were assigned staging (June 8) and stand-by (June 9) duties for two separate wildland fires.

On June 10, 2015, after about 7 hours of rest, the Superintendent arrived at his assigned guard station at 0800 hours for his 8-hour shift. Two crew leaders and four wildland fire fighters were working with 


\section{Wildland Fire Superintendent Dies From Heart Attack After Performing Physical Fitness Training - Idaho}

the Superintendent. Crewmembers conducted routine vehicle inspections, ran errands, and completed required daily physical training. The Superintendent participated in the management daily operations conference call. At 0830 hours the Superintendent started his daily physical training routine which consisted of a 1.8-mile run on a nearby trail with rolling hills. The Superintendent typically ran 11minute miles, expending about 9.3 metabolic equivalents [ExRx 2000; Ainsworth et al. 2011]. During his training, the outdoor temperature was estimated to be $77^{\circ}$ Fahrenheit with 43 percent relative humidity [NOAA 2015b]. After completing the run alone, the Superintendent entered the fire office (0850 hours). While conversing with crew members, the Superintendent collapsed (0856 hours) despite showing no signs or symptoms of heart problems.

The Superintendent experienced a 15-20 second seizure and appeared to briefly regain consciousness. Crewmembers attempted to assist him to his feet; he collapsed again and remained unconscious with labored breathing. 911 was called and two ambulances from neighboring communities started towards the guard station. An air evacuation medical helicopter was put on standby. The regional Agency dispatch center was notified and the Deputy Sheriff self-dispatched to the scene. At about 0904 hours, the Superintendent stopped breathing and crew members initiated CPR.

The Deputy arrived at 0906 hours and the ground ambulance arrived at 0908 hours. At this time the Superintendent was unresponsive, not breathing, and pulseless with CPR in progress. Ambulance paramedics initiated advanced life support, administered oxygen via bag-valve-mask, and placed an AED on the Superintendent's chest. Three shocks were administered with no change in the Superintendent's clinical status. A King Airway ${ }^{\circledR}$ was placed and proper tube placement verified by capnography [Neumar et al. 2010; EMSWorld 2011]. At 0919 hours, the Superintendent's cardiac monitor indicated asystole (no heart beat). An intravenous line was placed and cardiac resuscitation medications were administered by the paramedics.

At 0939 hours the medical helicopter arrived on-scene. The Superintendent's blood glucose reading was 97 milligrams per deciliter (normal is 60-115). Advanced life support continued for 8 additional minutes without any positive changes in the Superintendent's clinical status. At this time the paramedics from the ambulance and medical helicopter conferred with the on-call emergency department physician. The decision was made to pronounce the Superintendent dead at the scene (0947 hours). The County Coroner was notified and responded to the scene.

\section{Medical Findings}

The death certificate, completed by the County Coroner, and the autopsy report, completed by the Forensic Pathologist, listed the cause of death as "acute coronary artery thrombosis." The autopsy found a 100\% occlusion of the left anterior descending coronary artery with a blood clot (thrombus). The autopsy also revealed the Superintendent had left ventricular hypertrophy (LVH) and a borderline enlarged heart (cardiomegaly). See Appendix A for more complete information about autopsy findings.

The Superintendent had the following medical conditions: 


\section{Wildland Fire Superintendent Dies From Heart Attack After Performing Physical Fitness Training - Idaho}

Obesity - The Superintendent was 71 inches tall and weighed 230 pounds at his "pack test" in April 2015, giving him a body mass index of 32.1 kilograms per meters squared [CDC 2015].

Smoking - the Superintendent smoked about 10 cigarettes (1/2 pack) per day.

\section{Agency}

At the time of the NIOSH investigation, the Superintendent's Agency managed almost 12 million acres of public lands in Idaho. The Agency was comprised of four district offices, 12 field offices, and the Idaho State Office. The Superintendent's District Office managed almost 4 million acres. In addition to Agency land, through cooperative and mutual aid agreements, the District provided fire protection for lands administered by another federal agency; Idaho Department of Lands; county government; local city/rural fire departments; and a military base.

On average, between 100-110 wildfires are reported in the District, burning about 50,000 to 150,000 federal wildland acres each year. The Superintendent's District provided fire protection with 12 type IV wildland fire engines, three bulldozers, two water tenders, one helicopter, and one air attack platform. The fire engine resources are configured into three yard units, and three guard stations. All of these resources provide initial fire attack, extended attack, mutual aid, and fire dispatch assistance for the District.

Approximately 115 employees work in fire suppression within the District. Twenty of these employees are seasonal and the remainder are career-seasonal employees. The guard station is a seasonal office staffed with eight or nine employees between June and September/October. Career-seasonal employees, like the Superintendent, typically start their season at the District office and then transition to the guard station in June. During the spring season (until July), the district fire crews work 8-hour shifts (from 0800-1630) 5 days per week.

\section{Employment, Training, and Experience}

The Agency requires all wildland fire fighter applicants to be U.S. citizens, be 18 years of age or older prior to appointment, have a valid state driver's license for most positions, have a commercial drivers' license for some positions, pass a background check, and pass a medical evaluation (components described below). In addition, all arduous duty wildland fire fighters must pass an arduous duty work capacity test or "pack test" upon employment and annually thereafter. They also must complete basic certification (Fire fighter Type 2) and annual training depending on their specific job requirements.

The Superintendent was certified as a Division/Group Supervisor, Engine Boss (Single Resource), Basic Faller, Fire Fighter Type 1, Firing Boss (Single Resource), Helicopter Crewmember, Incident Commander Type 3, Strike Team Leader (Engine), and Task Force Leader. He had 14 years of 


\section{Wildland Fire Superintendent Dies From Heart Attack After Performing Physical Fitness Training - Idaho}

wildland fire fighting experience at locations throughout Idaho. He had been promoted to Superintendent in June 2015. This was his first season at this particular guard station.

The Superintendent was considered a career-seasonal wildland fire fighter (permanent employee). He worked for a private truck company and a heating, ventilation, and air conditioning contractor in the winter months. This season, he returned to work for the Agency on March 1, 2015. He completed his annual work capacity test on April 21, 2015. From March to June, he was stationed at the district office and took part in required physical training every day. He reported to the guard station for duty on June 1, 2015.

\section{Medical Evaluations}

Pre-employment/Preplacement Medical Evaluations

The Agency requires pre-employment/preplacement medical evaluations for all wildland fire fighters. Components of this evaluation currently include the following:

- Medical history questionnaire (self-reported)

- Complete medical history

- Physical examination (including vital signs)

- Complete blood count and blood chemistries

- Vision screen

- Audiogram

- Electrocardiogram (baseline)

- Spirometry (baseline)

- Psychiatric evaluation (see Appendix B)

The evaluation is performed by a contract physician. Once this evaluation is complete, the physician makes a determination regarding medical clearance for wildland fire fighting duties and forwards this decision to the Agency. The Superintendent had a pre-employment/preplacement medical evaluation when he joined the Agency in 2001.

Periodic Medical Evaluations

The Agency required all arduous duty wildland fire fighters to participate in a medical program which requires: a) a medical evaluation every 3 years and b) a self-reported health screening questionnaire completed by all permanent and seasonal fire fighters every other year. Components of the periodic medical evaluation include:

- Health Screen Questionnaire (see Appendix C)

- Complete medical history

- Physical examination (including vital signs)

- Complete blood count and blood chemistries

- Vision screen

- Audiogram

- Psychiatric evaluation (see Appendix B)

The medical evaluation, including the psychiatric evaluation, is performed by a contract physician. Once this evaluation is complete, the physician makes a determination regarding medical clearance 


\section{Wildland Fire Superintendent Dies From Heart Attack After Performing Physical Fitness Training - Idaho}

for fire fighting duties and forwards this decision to the Agency. If medical standards are not met, the member can submit a risk mitigation waiver for accommodations (light duty). The Superintendent's last periodic medical evaluation was in March 2014 and his last Health Screen Questionnaire was in April 2015. No medical issues or concerns were identified in the most recent evaluation or questionnaire.

\section{Wellness/Fitness Programs}

Fitness equipment (strength and aerobic) is available to all wildland fire fighters in the guard station. All wildland fire fighters must participate in a physical fitness program four out of five work days each week. Additionally, all fire personnel are required to complete the arduous duty pack test and the physical fitness test annually. The test includes a 1.5-mile run (target 10:30 minutes), pull-ups (target 7), sit-ups (target 45), and push-ups (target 25). The Superintendent participated in the Agency's required fitness program and usually alternated his activities between jogging and lifting weights. It was also reported that he bicycled and jogged during the off season and on days off to maintain his physical fitness.

\section{DISCUSSION}

\section{Sudden Cardiac Events}

In the United States, atherosclerotic coronary heart disease (CHD) is the most common risk factor for cardiac arrest and sudden cardiac death [Meyerburg and Castellanos 2008]. Risk factors for its development are grouped into non-modifiable and modifiable. Non-modifiable risk factors include age older than 45, male gender, and family history of coronary artery disease. Modifiable risk factors include diabetes mellitus, smoking, high blood pressure, high blood cholesterol, and obesity/physical inactivity [AHA 2016a; NHLBI 2015]. The Superintendent had one non-modifiable risk factor (male gender) and two modifiable CHD risk factors (smoking and obesity).

The narrowing of the coronary arteries by atherosclerotic plaques occurs over many years, typically decades [Libby 2013]. However, the growth of these plaques probably occurs in a nonlinear, often abrupt fashion. Heart attacks (myocardial infarctions) typically occur with the sudden development of complete blockage (occlusion) in one or more coronary arteries that have not developed a collateral blood supply. This sudden blockage is primarily due to blood clots (thromboses) forming on top of atherosclerotic plaques [Libby 2013]. Establishing a recent (acute) heart attack requires any of the following: characteristic EKG changes, elevated cardiac enzymes, or coronary artery thrombus. In this case, an acute coronary artery thrombus was revealed at autopsy, confirming a heart attack.

In the United States, the average age for a first heart attack in men is 65 [Harvard Health Publications 2009; Roger et al. 2012]. But as many as $4 \%$ to $10 \%$ of all heart attacks occur before age 45 , and most of these strike men [Kanitz et al. 1996; Harvard Health Publications 2009; Roger et al. 2012]. Many early studies evaluating these patients labeled them as having "premature" coronary artery disease, but it is now better understood as a rapidly progressive form of the disease [Klein and Nathan 2003]. Nonetheless, it is very unusual to have a heart attack at age 33. 


\section{Wildland Fire Superintendent Dies From Heart Attack After Performing Physical Fitness Training - Idaho}

The Superintendent had single vessel heart disease (i.e., in one coronary artery). Studies have revealed that patients with single vessel disease are younger, have fewer risk factors for CHD, and have a shorter duration of symptoms [Califf et al. 1983; Kanitz et al. 1996]. Smoking has been reported as the most common risk factor for acute myocardial infarction among young persons, although additional contributors include sympathomimetic drug use, cocaine use, cardiomyopathy, and coronary spasm [Kanitz et al. 1996; Klein and Nathan 2003]. The Superintendent did not use drugs or have cardiomyopathy, therefore coronary artery spasm is the most likely etiology for his heart attack. The causes and the mechanisms underlying the development of coronary artery spasm (CAS) are poorly defined and are likely multifactorial [Hung et al. 2014]. CAS occurs most often at rest, particularly from midnight to early morning [Hung et al. 2014]. If CAS lasts long enough, it can lead to angina and even myocardial infarction [Antman and Braunwald 2008; Hung et al. 2014].

Defibrillation is a process in which an electronic device gives an electric shock to the heart [AHA 2016b]. This helps reestablish normal contraction rhythms in a heart having a dangerous arrhythmia or in cardiac arrest. Small portable defibrillators, automated external defibrillators or AEDs, have become available to public safety agencies and are even placed in public places such as airports. It is necessary to integrate early defibrillation into an effective emergency cardiovascular care system [AHA 2016b]. The guard station where the Superintendent was assigned did not have an AED.

\section{Left Ventricular Hypertrophy and Borderline Cardiomegaly}

On autopsy, the Superintendent was found to have LVH and a mildly enlarged heart. Both conditions increase the risk for sudden cardiac death [Levy et al. 1990; Koren et al. 1991]. Hypertrophy of the heart's left ventricle is a relatively common finding among individuals with long-standing hypertension, a heart valve problem, or chronic cardiac ischemia (reduced blood supply to the heart muscle) [Siegel 1997]. It is unclear why the Superintendent had LVH and mild cardiomegaly, but given his left anterior descending lesion, chronic "silent” ischemia is a possibility.

\section{Physiological Stress of Fire Fighting and Training}

Heart attacks and sudden cardiac death can be triggered by heavy physical exertion [Mittleman 1993; Willich 1993; Albert et al. 2000]. Among structural fire fighters, sudden cardiac events have been associated with or triggered by alarm response, fire suppression, and heavy exertion during training (including physical fitness training) [Kales et al. 2003; Kales et al. 2007; NIOSH 2007]. The Superintendent's activities during physical fitness training expended about 9.3 metabolic equivalents, which is considered heavy physical activity [Gledhill and Jamnik 1992; Ainsworth et al. 2011]. The Superintendent's fatal heart attack was probably triggered by the physical exertion of fitness training.

\section{Recommendations}

The following recommendations address general safety and health issues and would not have prevented the Superintendent's death:

\section{Recommendation \#1: Provide preplacement and annual medical evaluations to all wildland fire}




\section{Wildland Fire Superintendent Dies From Heart Attack After Performing Physical Fitness Training - Idaho}

fighters consistent with 5 CFR 339, Medical Qualification Determinations, and NFPA 1582, Standard on Comprehensive Occupational Medical Program for Fire Departments.

Discussion: We applaud the Agency for developing and mandating a comprehensive preemployment/pre-placement medical evaluation and a periodic medical evaluation. The program could be strengthened by requiring annual medical evaluations for career and career-seasonal employees. The scope/content of the annual medical evaluation could vary depending on age. Of particular concern about the current program is the apparent lack of CHD risk assessment, such as the Framingham risk score, to identify members at risk for sudden cardiac events [ACC/AHA 2014]. NIOSH investigators encourage the Agency to review the most recent version of NFPA 1582 for guidance regarding the CHD risk assessment and need for further medical testing (e.g., EST) for fire fighters at medium to high risk of a sudden cardiac event. Although the Agency is not legally required to follow NFPA 1582, NIOSH investigators believe following these medical guidelines will reduce the risk of a wildland fire fighter suffering a medical emergency in the field, thus becoming a danger to themselves or others.

Recommendation \#2: Ensure that wildland fire fighters are cleared for duty by a physician knowledgeable about the physical demands of wildland fire fighting, the personal protective equipment used by wildland fire fighters, and the medical fitness for duty guidelines for fire fighters contained in NFPA 1582.

Discussion: The Agency contracts with local physicians to perform the pre-employment/pre-placement and periodic medical evaluations. It is unclear how much knowledge or experience the local physicians have regarding the job performance requirements or the medical fitness for duty needed for wildland fire fighters. It is also unclear how much guidance regarding these issues the Agency provides. The NIOSH investigators recommend the Agency review the medical fitness for duty criteria in NFPA 1582 and, if appropriate, provide this information to the contract physicians. NIOSH also recommends the Agency's medical director be involved in difficult cases.

\section{Recommendation \#3: Ensure automated external defibrillators are readily available as part of the basic life support equipment.}

Discussion: Preservation of human life is the primary responsibility of the fire department during fires and other emergencies. Fire departments should be prepared to perform rescue work and provide emergency care for those injured including persons experiencing cardiac arrest [NFPA 2010]. Most of the sudden cardiac deaths in the United States result from ventricular fibrillation. The chain of survival from cardiac arrest includes: (1) immediate recognition of cardiac arrest and activation of the emergency response system, (2) early CPR with an emphasis on chest compressions, (3) rapid defibrillation, (4) effective advanced life support, and (5) integrated post-cardiac arrest care [AHA 2016c]. Rapid defibrillation using AEDs has increased the cardiac arrest survival rate from 5\% (CPR performed only) to 26\% [AHA 2000]. When defibrillation is provided within 3 minutes, the survival rate is as high as 74\% [AHA 2005]. In this case, it took first responders 12 minutes to arrive on-scene. Placing an AED at the guard station or on fire apparatus would have reduced the time from collapse to first shock. The timely use of an AED, even by minimally trained first responders, can increase the likelihood of survival following cardiac arrest [Marenco et al. 2001; Koster 2002]. 


\section{Wildland Fire Superintendent Dies From Heart Attack After Performing Physical Fitness Training - Idaho}

\section{References}

ACC/AHA [2014]. ASCVD risk estimator. Washington, D.C.: American College of Cardiology/American Heart Association. [http://tools.acc.org/ASCVD-Risk-Estimator/]. Date accessed: May 2016.

AHA [2000]. Cardiopulmonary resuscitation statistics. Dallas, TX: American Heart Association.

AHA [2005]. Lay Rescuer Automated External Defibrillator (“Public Access Defibrillation”) Programs. Dallas, TX: American Heart Association.

[http://circ.ahajournals.org/content/111/24/3336.full]. Date accessed: May 2016.

AHA [2016a]. Understand your risk of heart attack. Dallas, TX: American Heart Association. [http://www.heart.org/HEARTORG/Conditions/HeartAttack/UnderstandYourRiskofHeartAttack/Unde rstand-Your-Risk-of-Heart-Attack_UCM_002040_Article.jsp]. Date accessed: May 2016.

AHA [2016b]. Defibrillation. Dallas, TX: American Heart Association.

[http://www.heart.org/HEARTORG/Conditions/Arrhythmia/PreventionTreatmentofArrhythmia/Defibr illation_UCM_305002_Article.jsp\#.V08Ua5jVxDM]. Date accessed: May 2016.

AHA [2016c]. Chain of survival. Dallas, TX: American Heart Association. [http://www.heart.org/HEARTORG/CPRAndECC/WhatisCPR/ECCIntro/Chain-ofSurvival_UCM_307516_Article.jsp]. Date accessed: May 2016.

Ainsworth BE, Haskell WL, Herrmann SD, Meckes N, Bassett DR Jr, Tudor-Locke C, Greer JL, Vezina J, Whitt-Glover MC, Leon AS [2011]. Compendium of physical activities: a second update of codes and MET values. Med Sci Sports Exerc 43(8):1575-1581.

Albert CM, Mittleman MA, Chae CU, Lee IM, Hennekens CH, Manson JE [2000]. Triggering of sudden death from cardiac causes by vigorous exertion. N Engl J Med 343(19):1355-1361.

Antman EM, Braunwald E [2008]. ST-segment elevation myocardial infarction. In: Fauci AS, Braunwald E, Kasper DL, Hauser SL, Longo DL, Jameson JL, Loscalzo J, eds. Harrison's principles of internal medicine. 17th ed. New York: McGraw-Hill, pp. 1532-1544.

CDC (Centers for Disease Control and Prevention) [2015]. Assessing your weight. [http://www.cdc.gov/healthyweight/assessing/index.html]. Date accessed: May 2016.

CFR. Code of Federal Regulations. Washington, DC: U.S. Government Printing Office, Office of the Federal Register.

Califf RM, Tomabechi Y, Lee KL, Phillips H, Pryor DB, Harrell FE Jr., Harris PJ, Peter RH, Behar VS, Kong Y, Rosati RA [1983]. Outcome in one-vessel coronary artery disease. Circ 67(2):283-290.

EMSWorld [2011]. Capnography as a clinical tool.

[http://www.emsworld.com/article/10287447/capnography-as-a-clinical-tool]. Date accessed: May 2016. 


\section{Wildland Fire Superintendent Dies From Heart Attack After Performing Physical Fitness Training - Idaho}

ExRx [2000]. Walk/run metabolic calculator. [http://www.exrx.net/Calculators/WalkRunMETs.html]. Date accessed: May 2016

Gledhill N, Jamnik VK [1992]. Characterization of the physical demands of firefighting. Can J Spt Sci 17(3):207-213.

Harvard Health Publications [2009]. Premature heart disease. [http://www.health.harvard.edu/hearthealth/premature-heart-disease]. Date accessed: May 2016.

Hung M-J, Hu P, Hung M-Y [2014]. Coronary artery spasm: review and update. Int J Med Sci 11(11):1161-1171.

IAFF, IAFC [2008]. The fire service joint labor management wellness/fitness initiative. 3rd ed. Washington, DC: International Association of Fire Fighters, International Association of Fire Chiefs.

Kales SN, Soteriades ES, Christoudias SG, Christiani DC [2003]. Firefighters and on-duty deaths from coronary heart disease: a case control study. Environ health: a global access science source. 2:14. [http://www.ehjournal.net/content/2/1/14]. Date accessed: May 2016.

Kales SN, Soteriades ES, Christophi CA, Christiani DC [2007]. Emergency duties and deaths from heart disease among fire fighters in the United States. N Engl J Med 356(12):1207-1215.

Kanitz MG, Giovannucci SJ, Jones JS, Mott M [1996]. Myocardial infarction in young adults: risk factors and clinical features. J Emer Med 14(2):139-145.

Klein L, Nathan S [2003]. Coronary artery disease in young adults. Editorial comment. J Am Col Cardiol 41(4):529-531.

Koren MJ, Devereux RB, Casale PN, Savage DD, Laragh JH (1991). Relation of left ventricular mass and geometry to morbidity and mortality in uncomplicated essential hypertension. Ann Intern Med 114(5): 345-352.

Koster RW [2002]. Automatic external defibrillator: key link in the chain of survival. J Cardiovasc Electrophysiol 13(1 Suppl):S92 95.

Levy D, Garrison RJ, Savage DD, Kannel WB, Castelli WP [1990]. Prognostic implications of echocardiographically determined left ventricular mass in the Framingham Heart Study. N Engl J Med 323(24):1706-1707.

Libby P [2013]. Mechanisms of acute coronary syndromes and their implications for therapy. N Engl J Med 368(21):2004-2013.

Marenco JP, Wang PJ, Link MS, Homoud MK, Estes NA 3rd [2001]. Improving survival from sudden cardiac arrest: the role of the automated external defibrillator. JAMA 285(9):1193-1200.

Mayo Clinic [2016]. Heart arrhythmias. [http://www.mayoclinic.com/health/heartarrhythmias/DS00290/METHOD=print\&DSECTION=all]. Date accessed: May 2016.

Meyerburg RJ, Castellanos A [2008]. Cardiovascular collapse, cardiac arrest, and sudden cardiac death. In: Fauci AS, Braunwald E, Kasper DL, Hauser SL, Longo DL, Jameson JL, Loscalzo J, eds. Harrison's principles of internal medicine. 17th ed. New York: McGraw-Hill, pp. 1707-1713. 


\section{Wildland Fire Superintendent Dies From Heart Attack After Performing Physical Fitness Training - Idaho}

Mittleman MA, Maclure M, Tofler GH, Sherwood JB, Goldberg RJ, Muller JE [1993]. Triggering of acute myocardial infarction by heavy physical exertion. N Engl J Med 329(23):1677-1683.

NFPA [2010]. Standard for providing fire and emergency services to the public. Quincy, MA: National Fire Protection Association. NFPA 1201.

NFPA [2013]. Standard on comprehensive occupational medical program for fire departments. Quincy, MA: National Fire Protection Association. NFPA 1582.

NFPA [2016]. Standard for wildland firefighting personnel professional qualifications. Quincy, MA: National Fire Protection Association. NFPA 1051.

NHLBI [2015]. Who is at risk for coronary artery disease? National Heart, Lung, and Blood Institute. [http://www.nhlbi.nih.gov/health/health-topics/topics/cad/atrisk.html]. Date accessed: May 2016.

NIOSH [2007]. NIOSH alert: preventing fire fighter fatalities due to heart attacks and other sudden cardiovascular events. [http://www.cdc.gov/niosh/docs/2007-133/]. Cincinnati, OH: U.S. Department of Health and Human Services, Centers for Disease Control and Prevention, National Institute for Occupational Safety and Health, DHHS (NIOSH) Publication No. 2007-133.

NOAA [2015a]. Quality controlled local climatological data: (final). Hourly observations table, Mountain Home AFB Airport, Mountain Home, ID June 7, 2015.

[http://cdo.ncdc.noaa.gov/qclcd/QCLCD]. Date accessed: May 2016.

NOAA [2015b]. Quality controlled local climatological data: (final). Hourly observations table, Mountain Home AFB Airport, Mountain Home, ID June 10, 2015. [http://cdo.ncdc.noaa.gov/qclcd/QCLCD]. Date accessed: May 2016.

Neumar RW, Otto CW, Link MS, Kronick SL, Shuster M, Callaway CW, Kudenchuk PJ, Ornato JP, McNally B, Silvers SM, Passman RS, White RD, Hess EP, Tang W, Davis D, Sinz E, Morrison LJ [2010]. Part 8: Adult advanced cardiovascular life support. 2010 American Heart Association Guidelines for cardiopulmonary resuscitation and emergency cardiovascular care. Dallas, TX: American Heart Association.

Roger VL, Go AS, Lloyd-Jones DM, Benjamin EJ, Berry JD, Borden WB, Bravata DM, Dai S, Ford ES, Fox CS, Fullerton HJ, Gillespie C, Hailpern SM, Heit JA, Howard DT, Kissela BM, Kittner SJ, Lackland DT, Lichtman JH, Lisabeth LD, Makuc DM, Marcus GM, Marelli A, Matchar DB, Moy CS, Mozaffarian D, Mussolino ME, Nichol G, Paynter NP, Soliman EZ, Sorlie PD, Sotoodehnia N, Turan TN, Virani SS, Wong ND, Woo D, Turner MB [2012]. Heart disease and stroke statistics - 2012 update: a report of the American Heart Association. Circulation 125(1):e2-e220.

Siegel RJ [1997]. Myocardial hypertrophy. In: Bloom S, ed. Diagnostic criteria for cardiovascular pathology acquired diseases. Philadelphia, PA: Lippencott-Raven, pp. 55-57.

Willich SN, Lewis M, Lowel H, Arntz HR, Schubert F, Schroder R [1993]. Physical exertion as a trigger of acute myocardial infarction. N Engl J Med 329(23):1684-1690.

Wong ND, Ridker PM [2000]. Thrombosis, inflammation, and infection. In: Wong ND, Black HR, Gardin JM, eds. Preventive Cardiology. New York: McGraw-Hill, pp. 269-286. 


\section{Wildland Fire Superintendent Dies From Heart Attack After Performing Physical Fitness Training - Idaho}

\section{Investigator Information}

This incident was investigated by the NIOSH Fire Fighter Fatality Investigation and Prevention Program, Cardiovascular Disease Component in Cincinnati, Ohio. Mr. Tommy Baldwin (MS) led the investigation and co-authored the report. Mr. Baldwin is a Safety and Occupational Health Specialist, a National Association of Fire Investigators (NAFI) Certified Fire and Explosion Investigator, an International Fire Service Accreditation Congress (IFSAC) Certified Fire Officer I, and a former Fire Chief and Emergency Medical Technician. Assisting Mr. Baldwin were Corey Butler (MS, REHS), an occupational safety and health specialist and coordinator of NIOSH's Wildland Fire Fighting Program and Christa Hale (DVM, MPH), a Senior Epidemiologist who works with Ms. Butler on wildland fire fighting research. Dr. Thomas Hales (MD, MPH) provided medical consultation and co-authored the report. Dr. Hales is a member of the NFPA Technical Committee on Occupational Safety and Health, and Vice-Chair of the Public Safety Medicine Section of the American College of Occupational and Environmental Medicine (ACOEM).

\section{Disclaimer}

Mention of any company or product does not constitute endorsement by the National Institute for Occupational Safety and Health (NIOSH). In addition, citations to Web sites external to NIOSH do not constitute NIOSH endorsement of the sponsoring organizations or their programs or products. Furthermore, NIOSH is not responsible for the content of these Web sites. 


\section{Wildland Fire Superintendent Dies From Heart Attack After Performing Physical Fitness Training - Idaho}

\section{Appendix A Autopsy Findings}

- Coronary artery atherosclerosis

o $100 \%$ occlusion of the left anterior descending coronary artery by fibrin clot

o Minimal focal narrowing of the left circumflex coronary artery

o Minimal focal narrowing of the right coronary artery

- Hypertensive heart disease

o Borderline cardiomegaly (heart weighed 468 grams [g]; predicted normal weight is $399 \mathrm{~g}$ [ranges between $302 \mathrm{~g}$ and $526 \mathrm{~g}$ as a function of sex, age, and body weight]) [Silver and Silver 2001]

o Left ventricular hypertrophy

- Left ventricle thickening (1.7 centimeter $[\mathrm{cm}])$

o Normal at autopsy is $0.76-0.88 \mathrm{~cm}$ [Colucci and Braunwald 1997]

o Normal by echocardiographic measurement is $0.6-1.0 \mathrm{~cm}$ [Connolly and Oh 2012]

- Normal cardiac valves

- No evidence of a pulmonary embolus (blood clot in the lung arteries)

- Negative blood test for drugs and alcohol

\section{REFERENCES}

Colucci WS, Braunwald E [1997]. Pathophysiology of heart failure. In: Braunwald, ed. Heart disease. 5th ed. Philadelphia, PA: W.B. Saunders Company, p. 401.

Connolly HM, Oh JK [2012]. Echocardiography. In: Bonow RO, Mann DL, Zipes DP, Libby P, Braunwald E, eds. Heart disease: a text of cardiovascular medicine. 9th ed. Vol. 1. Philadelphia, PA: Elsevier Saunders, p. 216.

Silver MM, Silver MD [2001]. Examination of the heart and of cardiovascular specimens in surgical pathology. In: Silver MD, Gotlieb AI, Schoen FJ, eds. Cardiovascular pathology. 3rd ed. Philadelphia, PA: Churchill Livingstone, pp. 8-9. 


\section{Wildland Fire Superintendent Dies From Heart Attack After Performing Physical Fitness Training - Idaho}

\section{Appendix B \\ Psychiatric Standard}

This standard relates (A) the fire fighter's need for judgment, mental functioning, and social/behavior skills with (B) the essential functions and work conditions of a wildland fire fighter, including working on small and large teams, flying in helicopters and fixed wing aircraft, and rapid pull out to safety zones under conditions that may include isolated or remote sites, snakes, close quarters with large numbers of other workers, limited and disrupter sleep, and long work hours. Some psychiatric conditions, including those listed in the standards, may not be compatible with safe and efficient performance of wildland fire fighter duties under these conditions.

The applicant/incumbent must have judgment, mental functioning, and social interaction/behavior that will provide for the safe and efficient conduct of the requirements of the job. This may be demonstrated by:

- No evidence by physical examination and medical history of psychiatric conditions (including alcohol or substance abuse) likely to present a safety risk or to worsen as a result of carrying out the essential functions of the job

Conditions which may result in disqualification include, but are not limited to, the following examples:

(All diagnoses must be consistent with the diagnostic criteria as established by the Diagnostic and Statistical Manual of Mental Disorders, Fourth Edition, DSM-IV).

1. Amnesiac disorders

2. Delirium (depending upon etiology and duration)

3. Dementias (depending upon etiology)

4. Dissociative Disorders

5. Kleptomania

6. Panic Disorder and Other Anxiety Disorders (depending upon etiology, duration, and severity of clinical expression)

7. Pyromania

8. Schizophrenia (exceptions may be made in cases of a single episode of schizophrenic reactions associated with an acute illness capable of causing such reaction) 


\section{Wildland Fire Superintendent Dies From Heart Attack After Performing} Physical Fitness Training - Idaho

9. Antisocial Personality Disorder 10. Paranoid Personality Disorder 11. Schizoid Personality Disorder

12. Organic Brain Syndrome

13. Any other condition not otherwise listed that may adversely affect safe and efficient job performance will be evaluated on a case-by-case basis. 


\section{Wildland Fire Superintendent Dies From Heart Attack After Performing Physical Fitness Training - Idaho}

\section{Appendix C}

USDA Forest Service/Department of the Interior FS-5100-31 (v 03/2013) OMB 0596-0164 (Expires 03/2016)

Health Screening Questionnaire (HSQ)

Assess your health needs by marking all true statements
WCT Level

Arduous

_.Moderate

_Light

The purpose is to identify individuals who may be at risk in taking the Work Capacity Test (WCT) and recommend an exercise program and/or medical examination prior to taking the WCT.

Employees are required to answer the following questions. The questions were designed, in consultation with occupational health physicians, to identify individuals who may be at risk when taking a WCT. The HSQ is not a medical examination. Any medical concerns you have that place you or your health at risk should be reviewed with your personal physician prior to participating in the WCT.

Check 'Yes' or 'No' in response to the following questions:

\begin{tabular}{|c|c|c|}
\hline [ ] $\mathrm{N}$ & 1) & $\begin{array}{l}\text { During the past } 12 \text { months have you at any time (during physical activity or while resting) } \\
\text { experienced pain, discomfort or pressure in your chest. }\end{array}$ \\
\hline [ ] $\mathrm{N}$ & 2) & $\begin{array}{l}\text { During the past } 12 \text { months have you experienced difficulty breathing or shortness of breath, } \\
\text { dizziness, fainting, or blackout? }\end{array}$ \\
\hline [ ] $\mathrm{N}$ & 3) & $\begin{array}{l}\text { Do you have a blood pressure with systolic (top \#) greater than } 140 \text { or diastolic (bottom \#) greater } \\
\text { than } 90 \text { ? }\end{array}$ \\
\hline [ ] $\mathrm{N}$ & 4) & $\begin{array}{l}\text { Have you ever been diagnosed or treated for any heart disease, heart murmur, chest pain (angina), } \\
\text { palpitations (irregular beat), or heart attack? }\end{array}$ \\
\hline [ ] $\mathrm{N}$ & 5) & $\begin{array}{l}\text { Have you ever had heart surgery, angioplasty, or a pace maker, valve replacement, or heart } \\
\text { transplant? }\end{array}$ \\
\hline [ ] & 6) & Do you have a resting pulse greater than 100 beats per minute? \\
\hline [ ] $\mathrm{N}$ & 7) & $\begin{array}{l}\text { Do you have any arthritis, back trouble, hip /knee/joint /pain, or any other bone or joint condition } \\
\text { that could be aggravated or made worse by the Work Capacity Test? }\end{array}$ \\
\hline [ ] $\mathrm{N}$ & 8) & $\begin{array}{l}\text { Do you have personal experience or doctor's advice of any other medical or physical reason that } \\
\text { would prohibit you from taking the Work Capacity Test? }\end{array}$ \\
\hline [ ] $\mathrm{N}$ & 9) & $\begin{array}{l}\text { Has your personal physician recommended against taking the Work Capacity Test because of } \\
\text { asthma, diabetes, epilepsy or elevated cholesterol or a hernia? }\end{array}$ \\
\hline
\end{tabular}

Regardless whether you are taking the Work Capacity test at the Arduous, Moderate or Light duty level, a "Yes" answer requires a determination from your personal physician stating that you are able to participate.

I understand that if I need to be evaluated by a physician, it will be based on the fitness requirements of the position(s) for which I am qualified. Signature: Printed Name Date

Unit: City State

Privacy Statement

The information obtained in the completion of this form is used to help determine whether an individual being considered for wildland firefighting can carry out those duties in a manner that will not place the candidate unduly at risk due to inadequate physical fitness and health. Its collection and use are covered under Privacy Act System of Records OPM/Govt-10 and are consistent with the provisions of 5 USC 552a (Privacy Act of 1974).

Paperwork Reduction Act Statement

According to the Paperwork Reduction Act of 1995, an agency may not conduct or sponsor, and a person is not required to respond to a collection of information unless it displays a valid OMB control number. The valid OMB control number for this information collection is 0596-0164. The time required to complete this information collection is estimated to average 5 minutes per response, including the time for reviewing instructions, searching existing data sources, gathering and maintaining the data needed, and completing and reviewing the collection of information. The U.S. Department of Agriculture (USDA) prohibits discrimination in all its programs and activities on the basis of race, color, national origin, gender, religion, age, disability, political beliefs, sexual orientation, and marital or family status. (Not all prohibited bases apply to all programs.) Persons with disabilities who require alternative means for communication of program information (Braille, large print, audiotape, etc.) should contact USDA's TARGET Center at 202-7202600 (voice and TDD). To file a complaint of discrimination, write USDA, Director, Office of Civil Rights, 1400 Independence Avenue, SW, Washington, DC 20250-9410 or call (800) 975-3272 (voice) or (202) 720-6382 (TDD). USDA is an equal opportunity provider and employer. 